\title{
Trends in antimicrobial resistance among clinical isolates of enterococci in a Brazilian tertiary hospital: a 4-year study
}

\author{
Evolução da resistência aos antimicrobianos entre isolados clínicos de enterococos em um \\ hospital terciário brasileiro: um estudo de 4 anos
}

\section{Natália Conceição ${ }^{1}$, Cristina da Cunha Hueb Barata de Oliveira ${ }^{2}$, Paulo Roberto da Silva ${ }^{1}$, Bárbara Godoi Melo Ávila ${ }^{1}$ and Adriana Gonçalves de Oliveira ${ }^{1}$}

\begin{abstract}
Introduction: In the past two decades members of the genus Enterococcus have emerged as important nosocomial pathogens worldwide. This study prospectively analyzed the distribution of species and trends in antimicrobial resistance among clinical isolates of enterococci in a Brazilian tertiary hospital from 2006-2009. Methods: Enterococcal species were identified by conventional biochemical tests. The antimicrobial susceptibility profile was performed by disk diffusion in accordance with the Clinical and Laboratory Standards Institute (CLSI). A screening test for vancomycin was also performed. Minimal inhibitory concentration (MIC) for vancomycin was determined using the broth dilution method. Molecular assays were used to confirm speciation and genotype of vancomycin-resistant enterococci (VRE). Results: A total of 324 non-repetitive enterococcal isolates were recovered, of which $87 \%$ were E. faecalis and $10.8 \%$ E. faecium. The incidence of E. faecium per 1,000 admissions increased significantly $(\mathrm{p}<0.001)$ from 0.3 in 2006 to 2.3 in 2009. The VRE rate also increased over time from $2.5 \%$ to $15.5 \%(\mathrm{p}<0.001)$. All VRE expressed high-level resistance to vancomycin (MIC $\geq 256 \mu \mathrm{g} /$ $\mathrm{mL}$ ) and harbored vanA genes. The majority (89.5\%) of VRE belonged to E. faecium species, which were characteristically resistant to ampicillin and quinolones. Overall, ampicillin resistance rate increased significantly from $2.5 \%$ to $21.4 \%$ from $2006-2009$. Resistance rates for gentamicin, chloramphenicol, tetracycline, and erythromycin significantly decreased over time, although they remained high. Quinolones resistance rates were high and did not change significantly over time. Conclusions: The data obtained show a significant increasing trend in the incidence of E. faecium resistant to ampicillin and vancomycin.
\end{abstract}

Keywords: Antimicrobial resistance profile. Enterococci. Vancomycin-resistant enterococci. Enterococcus faecium.

\section{RESUMO}

Introdução: Nas últimas duas décadas, os enterococos emergiram como importantes patógenos nosocomiais no mundo inteiro. Neste estudo, foi analisada a distribuição das espécies e a evolução da resistência aos antimicrobianos entre isolados clínicos de enterococos obtidos em um hospital terciário, no período de 2006 a 2009. Métodos: As espécies foram identificadas por testes bioquímicos convencionais e o perfil de sensibilidade foi determinado pelo método de disco difusão. A sensibilidade à vancomicina foi também determinada pela triagem em agar e pela concentração inibitória mínima (CIM). Testes moleculares foram utilizados para confirmar as espécies e determinar os genótipos dos enterococos resistentes à vancomicina (VRE). Resultados: Foram analisadas 324 amostras de enterococos, sendo $87 \%$ E. faecalis e 10,8\% E. faecium. A incidência de E. faecium por 1.000 pacientes internados aumentou significativamente $(p<0,001)$ de 0,3 em 2006 para 2,3 em 2009. A taxa de VRE também aumentou significativamente de 2,5\% para 15,5\% ( $<<0,001)$. Todos os VRE apresentaram genótipo VanA e CIM $\geq 256 \mu \mathrm{g} / \mathrm{mL}$ para vancomicina. A maioria $(89,5 \%)$ dos VRE pertencia à espécie E. faecium e foram resistentes à ampicilina e quinolonas. Foi observado um aumento significativo na taxa de resistência à ampicilina, de 2,5\% (2006) para 21,4\% (2009). As taxas de resistência para gentamicina, cloranfenicol, tetraciclina e eritromicina diminuíram significativamente no período do estudo. Para as quinolonas, as taxas de resistência foram elevadas não alteraram significativamente, no período do estudo. Conclusões: Os resultados do presente estudo mostram um aumento significativo na incidência de E. faecium resistentes à ampicilina e vancomicina.

Palavras-chaves: Perfil de resistência a antimicrobianos. Enterococos. Enterococos resistentes à vancomicina. Enterococcus faecium.

1. Departamento de Ciências Biológicas, Universidade Federal do Triângulo Mineiro, Uberaba, MG. 2. Departamento de Clínica Médica, Universidade Federal do Triângulo Mineiro, Uberaba, MG.

Address to: Dra. Adriana Gonçalves de Oliveira. DCB/UFTM. Praça Manoel Terra 330, 38015-050 Uberaba, MG, Brasil.

Phone: 5534 3318-5480; Fax: $55343318-5462$

e-mail: agoliveira@dcb.uftm.edu.br

Received in 22/10/2010

Accepted in 17/11/2010

\section{INTRODUCTION}

Enterococci are widespread in nature and are normal constituents of the human gastrointestinal tract, but nowadays they have been recognized as important pathogens, especially among hospitalized patients. Enterococci may cause a range of different disorders, such as urinary tract infections, intraabdominal abscesses, wound infections, endocarditis and bacteraemia ${ }^{1}$. According to the SENTRY Antimicrobial Surveillance Program, enterococci are the fourth most common pathogen of bacteremia in North America and the fifth in Europe $^{2}$. In Brazil, they are the eighth agent of bacteremia overall and the third among the Grampositive cocci ${ }^{3}$.

Intrinsic or acquired resistance to various commonly used antimicrobial agents is a remarkable characteristic of enterococci ${ }^{4}$. Acquired resistance to glycopeptides (vancomycin and teicoplanin), penicillins and aminoglycosides (high-level resistance) are the most clinically important, because therapeutic options in these cases are limited.

Six types of acquired vancomycin resistance have been reported in enterococci; however, the most prevalent are VanA and VanB, in which the genes encoding resistance are associated with mobile genetic elements that allow resistance to spread clonally and laterally ${ }^{5}$. The VanC type confers an intrinsic nontransferable low-level resistance to vancomycin that has been observed primarily in Enterococcus gallinarum and Enterococcus casseliflavus.

Clinical vancomycin-resistant enterococci (VRE) isolates were first recognized in the 1980s in Europe and USA ${ }^{4}$. Approximately ten years later, the first VRE were isolated in Brazil, in the States of Paraná and São Paulo, located in the southern and southeastern regions of the country, respectively $y^{6,7}$. Although these VRE isolates belong to Enterococcus faecium species, until recently in Brazil, Enterococcus faecalis was the predominant VRE commonly reported in hospitals in the State of São Paulo ${ }^{8-13}$. 
Despite the increasing number of reports regarding the evolution of antimicrobial resistance of enterococci in different countries, published data on this subject are still sporadic in Brazil. In this study, our group analyzed the distribution of species and trends in antimicrobial resistance among enterococci recovered from clinical specimens in a Brazilian tertiary hospital over a four-year period. The genotypes of VRE isolates were also determined.

\section{METHODS}

\section{Study design}

A prospective study was conducted from 2006 to 2009 in the hospital of the Triangulo Mineiro University Hospital of the Federal University (Universidade Federal do Triângulo Mineiro, UFTM). This hospital, located in the State of Minas Gerais in southeastern Brazil, is a 294-bed tertiary-care teaching hospital with a 40-bed intensive care unit (ICU) and a full range of medical specialties. Over the study period, an average of 11,000 patients were admitted annually. All enterococci isolates recovered from hospitalized patients were included in the study, but only the first isolate from each patient was used.

\section{Phenotypic identification of Enterococcus species}

Isolates were identified at genus level by Gram staining, cellular morphology, absence of catalase production, hydrolysis of L-pyrrolidonyl- $\beta$-naphthylamide (PYR test), hydrolysis of esculin in presence of bile salts (bile-esculin test) and tolerance to $6.5 \%$ $\mathrm{NaCl}$. Species identification was determined based on tests of carbohydrate fermentation, arginine hydrolysis, mobility, yellow pigment production and growth in $0.04 \%$ tellurite $^{14}$.

\section{Susceptibility testing}

The antimicrobial susceptibility profile was performed using the disk diffusion method. The antimicrobials agents tested were: vancomycin $(30 \mu \mathrm{g})$, teicoplanin $(30 \mu \mathrm{g})$, ampicillin $(10 \mu \mathrm{g})$, penicillin $(10 \mathrm{U})$, streptomycin $(300 \mu \mathrm{g})$, gentamicin $(120 \mu \mathrm{g})$, norfloxacin $(10 \mu \mathrm{g})$, ciprofloxacin $(5 \mu \mathrm{g})$, chloramphenicol $(30 \mu \mathrm{g})$, tetracycline $(30 \mu \mathrm{g})$, and erythromycin $(15 \mu \mathrm{g})$. Beta-lactamase production was tested with chromogenic nitrocefin disk (Becton, Dickinson and Company, Cefinase ${ }^{\mathrm{TM}}, \mathrm{USA}$ ), in accordance with the manufacturer's instructions. A screening test for vancomycin was performed on BHI agar supplemented with $6 \mu \mathrm{g} / \mathrm{mL}$ of this drug for all enterococcal isolates. For isolates resistant according to the screening test, the minimal inhibitory concentration (MIC) for vancomycin was determined using the broth dilution method. All susceptibility tests were performed and interpreted according to guidelines established by the Clinical and Laboratory Standards Institute (CLSI) ${ }^{15}$. Staphylococcus aureus ATCC (American Type Culture Collection) 25923, S. aureus ATCC 29213, and E. faecalis ATCC 29212 were used for quality control.

\section{Molecular testing}

Bacterial DNA was extracted from the enterococcal isolates that were phenotypically resistant to vancomycin using the QIAamp ${ }^{\otimes}$ DNA Mini kit (Qiagen, Hilden, Germany), in accordance with the manufacturer's guidelines. Detection of vancomycin resistance genes was performed by a multiplex polymerase chain reaction (PCR) assay, in accordance with procedures described ${ }^{16}$ by Woodford et al. Species identification of VRE isolates was confirmed by PCR, as described previously ${ }^{17}$. PCR products were analyzed by electrophoresis on $1.5 \%$ agarose gels and stained by ethidium bromide.

\section{Statistical analysis}

To evaluate the trend in antimicrobial resistance among enterococci over time, the $\chi^{2}$-test for trend was performed using Epi Info (CDC, Atlanta, GA) statistical software (version 3.5.1). The significance level was set at $\mathrm{p} \leq 0.05$.

\section{Ethical considerations}

The present study was approved by Research Ethics Committee of the UFTM.

\section{RESULTS}

A total of 324 non-repetitive enterococcal isolates were consecutively recovered during the study period. These isolates were recovered from different clinical specimens, but they were more frequent in wounds (38.9\%) and in urine (29.9\%). Table 1 shows the distribution of enterococcal species according to clinical specimens. The species identified were E. faecalis (87\%), E. faecium (10.8\%), E. casseliflavus (1.2\%), E. gallinarum (0.3\%), E. hirae (0.3\%) and E. pseudoavium (0.3\%).

Figure 1 shows the incidence of E. faecalis, E. faecium and other enterococcal species per 1,000 patient admissions from 2006 to 2009. A significant increasing trend in the incidence of $E$. faecium ( $p<0.001$ ) from 0.3 in 2006 to 2.3 in 2009 was observed, but not of E. faecalis or other enterococcal species over time.

The rate of VRE also increased significantly over time ( $\mathrm{p}<0.001)$, from $2.5 \%$ in 2006 to $15.5 \%$ in 2009 in our institution, although in 2007 there were no VRE and in 2008 the rate was only $1.4 \%$ (Table 2). Among the 19 VRE isolates, 2 (10.5\%) were identified phenotypically and by PCR as E. faecalis (VREfs) and 17 (89.5\%)

TABLE 1 - Distribution of Enterococcus species isolated from hospitalized patients from 2006 to 2009, according to clinical specimens.

\begin{tabular}{|c|c|c|c|c|c|c|c|c|c|c|c|c|c|c|}
\hline \multirow[b]{3}{*}{ Species } & \multicolumn{12}{|c|}{ Clinical specimens } & & \\
\hline & \multicolumn{2}{|c|}{ wounds } & \multicolumn{2}{|c|}{ urine } & \multicolumn{2}{|c|}{ secretions } & \multicolumn{2}{|c|}{ blood } & \multicolumn{2}{|c|}{ catheter } & \multicolumn{2}{|c|}{ other } & \multicolumn{2}{|c|}{ Total } \\
\hline & $\mathrm{n}$ & $\%$ & $\mathrm{n}$ & $\%$ & $\mathrm{n}$ & $\%$ & $\mathrm{n}$ & $\%$ & $\mathrm{n}$ & $\%$ & $\mathrm{n}$ & $\%$ & $\mathrm{n}$ & $\%$ \\
\hline Enterococcus faecalis & 117 & 41.5 & 80 & 28.4 & 45 & 16.0 & 19 & 6.7 & 14 & 5.0 & 7 & 2.5 & 282 & 87.0 \\
\hline Enterococcus faecium & 6 & 17.1 & 16 & 45.7 & 9 & 25.7 & 4 & 11.4 & - & - & - & - & 35 & 10.8 \\
\hline Enterococcus casseliflavus & is 2 & 50.0 & - & - & 2 & 50.0 & - & - & - & - & - & - & 4 & 1.2 \\
\hline Enterococcus gallinarum & - & - & - & - & - & - & - & - & - & - & 1 & 100.0 & 1 & 0.3 \\
\hline Enterococcus hirae & - & - & 1 & 100.0 & - & - & - & - & - & - & - & - & 1 & 0.3 \\
\hline Enterococcus pseudoavium & 1 & 100.0 & - & - & - & - & - & - & - & - & - & - & 1 & 0.3 \\
\hline Total (\%) & 126 & 38.9 & 97 & 29.9 & 56 & 17.3 & 23 & 7.1 & 14 & 4.3 & 8 & 2.5 & 324 & 100.0 \\
\hline
\end{tabular}




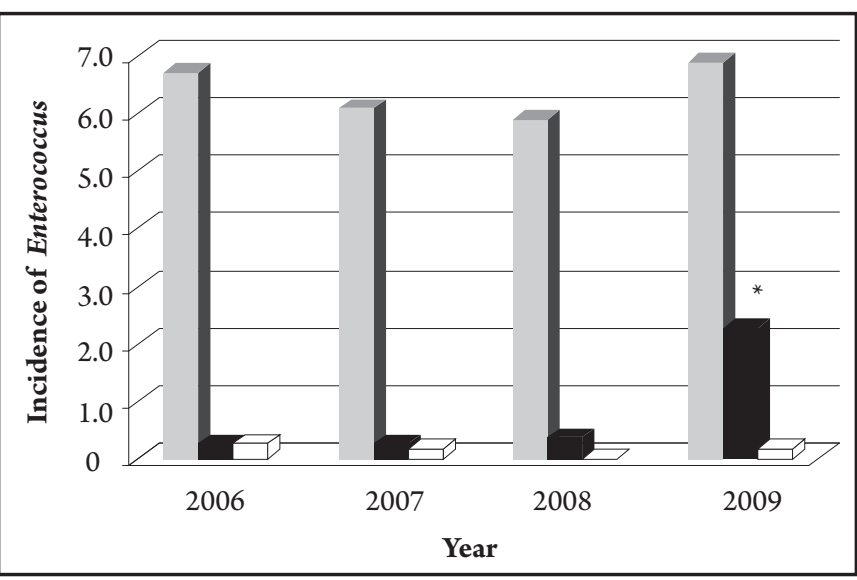

FIGURE 1 - Incidence of Enterococcus faecalis (gray bars), Enterococcus faecium (black bars) and others species of Enterococcus (white bars) per 1,000 patient admissions from 2006 to 2009. ${ }^{*} \chi^{2}$ for trend $p<0.001$.

as E. faecium (VREfm). The first two VREfs were isolated in 2006. Thereafter, no other VREfs were isolated during the study period. The first VREfm appeared at the end of 2008, since then an increasing number of VREfm were noted in 2009.

All VRE isolates uniformly harbored vanA genes, as demonstrated by PCR. They were resistant to teicoplanin and expressed highlevel resistance to vancomycin $(\mathrm{MIC} \geq 256 \mu \mathrm{g} / \mathrm{mL})$. The two VREfs showed the same antimicrobial susceptibility profile characterized by resistance to norfloxacin, ciprofloxacin, chloramphenicol, tetracycline, and erythromycin, and susceptibility to ampicillin, penicillin, streptomycin, and gentamicin. All VREfm were resistant to ampicillin, penicillin, norfloxacin, ciprofloxacin, and erythromycin and susceptible to streptomycin, gentamicin, chloramphenicol, and tetracycline.

Enterococcus gallinarum $(\mathrm{n}=1)$ and E. casseliflavus $(\mathrm{n}=4)$ isolates were susceptible to vancomycin by the disk diffusion method, but grew on agar screening with $6 \mu \mathrm{g} / \mathrm{mL}$ of vancomycin, while the MIC observed for this drug was $8 \mu \mathrm{g} / \mathrm{mL}$. These five isolates were not considered as VRE in this study.

As demonstrated in Table 2, ampicillin and penicillin resistance rates increased from 2006 to 2009 from $2.5 \%$ to $21.4 \%$ and $23.8 \%$ to $35.9 \%$, respectively, but only the increasing rate of ampicillin was statistically significant $(\mathrm{p}<0.001)$. Among the 282 E. faecalis and 35 E. faecium isolates, 4 (1.4\%) and 25 (77.4\%) of them, respectively, were resistant to ampicillin and to penicillin. However, 63 (22.3\%) E. faecalis isolates were resistant to penicillin, but remained susceptible to ampicillin. Beta-lactamase producing isolates were not detected.

Rates ofresistancetogentamicin (41.2\% to $25.2 \%$ ), chloramphenicol ( $55 \%$ to $29.1 \%$ ), tetracycline ( $75 \%$ to $57.3 \%$ ), and erythromycin ( $95 \%$ to $80.6 \%$ ) significantly decreased from 2006 to 2009 , as demonstrated in Table 2. Regarding streptomycin, norfloxacin and ciprofloxacin, the resistance rates did not change significantly over the four-year study period.

\begin{tabular}{|c|c|c|c|c|c|c|c|c|c|}
\hline \multirow[b]{3}{*}{ Antimicrobial agent } & \multicolumn{8}{|c|}{ Resistant isolates per year (number/\%) } & \multirow[b]{3}{*}{ p-value } \\
\hline & \multicolumn{2}{|c|}{$2006(\mathrm{n}=80)$} & \multicolumn{2}{|c|}{$2007(\mathrm{n}=72)$} & \multicolumn{2}{|c|}{$2008(\mathrm{n}=69)$} & \multicolumn{2}{|c|}{$2009(\mathrm{n}=103)$} & \\
\hline & $\mathrm{n}$ & $\%$ & $\mathrm{n}$ & $\%$ & $\mathrm{n}$ & $\%$ & $\mathrm{n}$ & $\%$ & \\
\hline Vancomycin & 2 & 2.5 & - & - & 1 & 1.4 & 16 & 15.5 & $<0.001$ \\
\hline Teicoplanin & 2 & 2.5 & - & - & 1 & 1.4 & 16 & 15.5 & $<0.001$ \\
\hline Ampicillin & 2 & 2.5 & 2 & 2.8 & 3 & 4.3 & 22 & 21.4 & $<0.001$ \\
\hline Penicillin & 19 & 23.8 & 18 & 25.0 & 19 & 27.5 & 37 & 35.9 & 0.059 \\
\hline Streptomycin & 24 & 30.0 & 13 & 18.1 & 22 & 31.9 & 28 & 27.9 & 0.861 \\
\hline Gentamicin & 33 & 41.2 & 21 & 29.2 & 22 & 31.9 & 26 & 25.2 & 0.037 \\
\hline Norfloxacin & 60 & 75.0 & 39 & 54.2 & 45 & 65.2 & 66 & 64.1 & 0.351 \\
\hline Ciprofloxacin & 62 & 77.5 & 37 & 51.4 & 45 & 65.2 & 63 & 61.2 & 0.124 \\
\hline Chloramphenicol & 44 & 55.0 & 33 & 45.8 & 25 & 36.2 & 30 & 29.1 & $<0.001$ \\
\hline Tetracycline & 60 & 75.0 & 49 & 68.1 & 39 & 56.5 & 59 & 57.3 & 0.006 \\
\hline Erythromycin & 76 & 95.0 & 65 & 90.3 & 59 & 85.5 & 83 & 80.6 & 0.002 \\
\hline
\end{tabular}

\section{DISCUSSION}

Although there are at least 30 species of the genus Enterococcus, both E. faecalis and E. faecium are the most common species causing human infections ${ }^{1,14}$. Similarly, in this study, E. faecalis was the most prevalent species followed by E. faecium, while the other species were rarely recovered from clinical specimens. Nevertheless, a significant increasing trend in the incidence of E. faecium per 1,000 patient admissions from 0.3 in 2006 to 2.3 in 2009 was verified, approximately an eight-fold increase. In a study conducted in a hospital in Greece, the authors reported a similar increased incidence of E. faecium infections ( 0.7 in 2002 to 2.4 in 2007), although that hospital is larger than ours, with more than 60,000 admissions annually ${ }^{18}$.
The vancomycin-resistant enterococci rate also increased in our institution, by almost the same proportion as the incidence of $E$. faecium incidence. Most (89.5\%) of the VRE isolates were E. faecium exhibiting the van $A$ genotype. In a retrospective study conducted at a tertiary Brazilian hospital located in the State of São Paulo, Furtado et al. also showed an increase in the rate of VRE over time from $9.5 \%$ in 2000 to $14.7 \%$ in 2001 and to $15.8 \%$ in 2002 . However, the authors did not identify the VRE species or genotypes ${ }^{19}$. According to more recent data from the SENTRY Program, the percentage of VRE in Brazil increased from $6.9 \%$ in 2003 to $31.1 \%$ in 2008 and the majority (68.5\%) of these isolates were $E$. faecium ${ }^{20}$. These VRE rates are much higher than that observed in other Latin America countries and in our hospital.

In the last two decades, the importance of E. faecium as a nosocomial pathogen has increased throughout the world due to 
the greater ability of this species to acquire resistance to multiple drugs than E. faecalis. Molecular epidemiological studies have reported the spread of a hospital-adapted complex of E. faecium designated as clonal complex-17 (CC-17), which is associated with the majority of hospitals outbreaks and clinical infections on all continents ${ }^{21,22}$. This complex is characterized by ampicillin and quinolones resistance and by the presence of a putative pathogenicity island. Currently, the increase in E. faecium resistant to ampicillin usually precedes increasing rates of VREfm in various locations around the world, especially in certain European countries, where until recently, VRE rates were $\operatorname{low}^{4,23-26}$. In the USA, since the 1990s, E. faecium isolates account for more than $95 \%$ of all VRE recovered and most of them are also resistant to ampicillin ${ }^{24}$.

Likewise, our group observed a significant increasing trend in resistance to ampicillin among clinical isolates of enterococci due to increased incidence of E. faecium in our institution, since resistance rates to this drug among E. faecium (71.4\%) were much higher than among E. faecalis (1.4\%) isolates. Of note, all VREfm isolated in this study were resistant to both ampicillin and quinolones, showing the same antimicrobial resistance profile observed for E. faecium of CC-17. Nevertheless, molecular epidemiological studies conducted with Brazilian E. faecium isolates from several hospitals showed that this complex is not common in our country ${ }^{27,28}$.

In contrast to trends in ampicillin resistance, a significant decrease in resistance rates to chloramphenicol and tetracycline occurred from 2006 to 2009 and it is probably related to the increasing incidence of E. faecium in the present study. Decreasing rates of chloramphenicol resistance among enterococci has previously been observed from 1997 to 1999 in the USA (19\% to $12 \%$ ) and Latin America (34\% to 27\%), according to the SENTRY Program ${ }^{29}$. In addition, all VREfm isolates during this study were uniformly susceptible to both drugs. A similar chloramphenicol resistance rate among VREfm of $0.5 \%$ was observed in North America ${ }^{21}$; however, chloramphenicol use for the treatment of VRE infections is known to result in the development of resistance ${ }^{30}$.

Regarding tetracycline, although the enterococci resistance rate decreased over time, it remained high in 2009 (57\%), but was slightly lower than that reported by the SENTRY Program for Latin America $(67.2 \%)^{31}$ and by other Brazilian studies performed with clinical enterococci strains isolated in 1996 and $1997(62 \%)^{32}$ and in 2006 and $2007(66.5 \%)^{8}$. Likewise, the resistance rates to erythromycin were very high, despite the significant decrease observed (95\% to $80.6 \%)$, confirming that resistance to this drug is very common among enterococci ${ }^{1,8,31,33}$.

Overall, moderate rates of high-level resistance to aminoglycosides were observed over the four-year, similar to those observed recently in Brazil of $32.1 \%$ and $26.7 \%$ and in the USA of $30.6 \%$ and $25.2 \%$ for streptomycin and gentamicin, respectively ${ }^{3,34}$. Regarding quinolones, resistance rates did not change significantly during the study period, whereas the overall resistance rates to ciprofloxacin were slightly higher compared to Latin America (50\%) and the USA (58\%) ${ }^{29,31}$.

In conclusion, the present data show an increasing incidence of E. faecium resistant to ampicillin and vancomycin, corroborating the worldwide trends. Considering that all the VREfm identified in our institution expressed resistance to ampicillin and quinolone, it is quite probable that they belong to the hospital-adapted CC-17. However, future molecular characterization is necessary to verify this, since there are no studies demonstrating the spread of E. faecium $\mathrm{CC}-17$ in Brazil to date. Therefore, more rigorous strategies should be developed in order to prevent further spread of E. faecium in Brazil.

\section{ACKNOWLEDGMENTS}

The authors would like to thank the Clinical Pathology Laboratory staff at the Triangulo Mineiro Federal University (Minas Gerais, Brazil) for providing the enterococci isolates.

\section{CONFLICT OF INTEREST}

The authors declare that there is no conflict of interest.

\section{FINANCIAL SUPPORT}

Fundação de Amparo à Pesquisa do Estado de Minas Gerais and the Fundação de Ensino e Pesquisa de Uberaba.

\section{REFERENCES}

1. Murray BE. The life and times of the Enterococcus. Clin Microbiol Rev 1990; 3:46-65.

2. Biedenbach DJ, Moet GJ, Jones RN. Occurrence and antimicrobial resistance pattern comparisons among bloodstream infection isolates from the SENTRY Antimicrobial Surveillance Program (1997-2002). Diagn Microbiol Infect Dis 2004; 50:56-69.

3. Gales AC, Sader HS, Ribeiro J, Zoccoli C, Barth A, Pignatari AC. Antimicrobial susceptibility of gram-positive bacteria isolated in Brazilian hospitals participating in the SENTRY Program (2005-2008). Braz J Infect Dis 2009; 13:90-98.

4. Murray BE. Vancomycin-resistant enterococcal infections. N Engl J Med 2000; 342:710-721.

5. Courvalin P. Genetics of glycopeptide resistance in gram-positive pathogens. Int J Med Microbiol 2005; 294:479-486.

6. Dalla-Costa LM, Souza DC, Martins LTF, Zanella RC, Brandileone MC, Bokermann S, et al. Vancomycin-resistant Enterococcus faecium: first case in Brazil. Braz J Infect Dis 1998; 2:160-163.

7. Zanella RC, Valdetaro F, Lovgren M, Tyrrel GJ, Bokermann S, Almeida SC, et al. First confirmed case of a vancomycin-resistant Enterococcus faecium with vanA phenotype from Brazil: isolation from a meningitis case in São Paulo. Microb Drug Resist 1999; 5:159-162.

8. Bender EA, Freitas ALP, Reiter KC, Lutz L, Barth AL. Identification, antimicrobial resistance and genotypic characterization of Enterococcus spp. isolated in Porto Alegre, Brazil. Braz J Microbiol 2009; 40:693-700.

9. Caiaffa Filho HH, Almeida GD, Oliveira GA, Sarahyba L, Mamizuka EM, Burattini MN. Molecular characterization of van genes found in vancomycin resistant Enterococcus spp. isolated from Hospital das Clínicas, FMUSP, São Paulo, Brazil. Braz J Infect Dis 2003; 7:173-174.

10. Cereda RF, Sader HS, Jones RN, Sejas L, Machado AM, Zanatta YP, Rego STMS, Medeiros EAS. Enterococcus faecalis resistant to vancomycin and teicoplanin (VanA phenotype) isolated from a bone marrow transplanted patient in Brazil. Braz J Infect Dis 2001; 5:40-46.

11. Cordeiro JC, Silbert S, Reis AO, Sader HS. Inter-hospital dissemination of glycopeptides resistant Enterococcus faecalis in Brazil. Clin Microbiol Infect 2004; 3:260-262.

12. Ribas RM, Darini ALC, Moreira TA, Freitas C, Gontijo Filho PP. Vancomycinresistant vanA phenotype Enterococcus faecalis: first case in Minas Gerais state and epidemiological considerations. Braz J Infec Dis 2007; 11:439-440.

13. Zanella RC, Brandileone MCC, Bokermann S, Almeida SCG, Valdetaro F, Vitório F, et al. Phenotypic and genotypic characterization of vanA Enterococcus isolated during the first nosocomial outbreak in Brazil. Microb Drug Resist 2003; 9:283-291.

14. Teixeira LM, Carvalho MGS, Facklam RR. Enterococcus. In: Murray BE, Baron EJ, Jorgensen JH, Landry ML, Pfaller MA, editors. Manual of Clinical Microbiology. Washington (DC): American Society for Microbiology; 2007. p. 430-442.

15. Clinical and Laboratory Standards Institute. Performance standards for antimicrobial susceptibility testing. Ninth tenth Informational Supplement. Wayne: CLSI document M100-S19; 2009. 
16. Woodford N, Morrison D, Johnson AP, Briant V, George RC, Cookson B. Application of DNA probes for rRNA and vanA genes to investigation of a nosocomial cluster of vancomycin-resistant enterococci. J Clin Microbiol 1993; 31:653-658.

17. Dutka-malen S, Evers S, Courvalin P. Detection of glicopeptide resistance genotypes and identification to the species level of clinically relevant enterococci by PCR. J Clin Microbiol 1995; 33:24-27.

18. Protonotariou E, Dimitroulia E, Pournaras S, Pitiriga V, Sofianou D, Tsakris A. Trends in antimicrobial resistance of clinical isolates of Enterococcus faecalis and Enterococcus faecium in Greece between 2002 and 2007. J Hosp Infect 2010; 75:225-227.

19. Furtado GHC, Martins ST, Coutinho AN, Soares GMM, Wey SB, Medeiros EAS Incidence of vancomycin-resistance Enterococcus at a university hospital in Brazil. Rev Saude Publica 2005; 39:41-46.

20. Sader HS, Moet GJ, Jones RN. Antimicrobial resistance among gram-positive bacteria isolated in Latin American hospitals. J Chemother 2009; 21:611-620.

21. Deshpande LM, Fritsche TR, Moet GJ, Biendenbach DJ, Jones RN. Antimicrobial resistance and molecular epidemiology of vancomycin-resistant enterococci from North America and Europe: a report from the SENTRY Antimicrobial Surveillance Program. Diagn Microbiol Infect Dis 2007; 58:163-170.

22. Leavis HL, Bonten MJM, Willems RJL. Identification of high-risk enterococcal clonal complexes: global dispersion and antibiotic resistance. Curr Opin Microbiol 2006; 9:454-460.

23. Oteo J, Cuevas O, Navarro C, Aracil B, Campos J. Trends in antimicrobial resistance in 3469 enterococci isolated from blood (EARSS experience 200106, Spain): increasing ampicillin resistance in Enterococcus faecium. J Antimicrob Chemother 2007; 59:1044-1045.

24. Shepard BD, Gilmore MS. Antibiotic-resistant enterococci: the mechanisms and dynamics of drug introduction and resistance. Microbes Infect 2002; 4:215-224.

25. Treitman AN, Yarnold PR, Warren J, Noskin GA. Emerging incidence of Enterococcus faecium among hospital isolates (1993 to 2002). J Clin Microbiol $2005 ; 43: 462-463$.

26. Werner G, Coque TM, Hammerum AM, Hope R, Hryniewicz W, Johnson A et al. Emergence and spread of vancomycin resistance among enterococci in Europe. Euro Surveill 2008; 13:1-11.

27. Camargo ILBC, Gilmore MS, Darini ALC. Multilocus sequence typing and analysis of putative virulence factors in vancomycin-resistant and vancomycinsensitive Enterococcus faecium isolates from Brazil. Clin Microbiol Infect 2006; 12:1123-1130.

28. Titze-de-Almeida R, Van Belkum A, Felipe MSS, Zanella RC, Top J, Willems RJL. Multilocus sequence typing of hospital associated Enterococcus faecium from Brazil reveals their unique evolutionary history. Microb Drug Res 2006; 12:121-125.

29. Low DE, Keller N, Barth A, Jones RN. Clinical prevalence, antimicrobial susceptibility, and geographic resistance patterns of Enterococci: results from the SENTRY Antimicrobial Surveillance Program, 1997-1999. Clin Infect Dis 2001; 32:S133-145.

30. Lautenbach E, Gould CV, LaRosa LA, Marr AM, Nachamkin I, Bilker WB, et al. Emergence of resistance to chloramphenicol among vancomycin-resistant enterococcal (VRE) bloodstream isolates. Intern J Antimicrob Agents 2004; 23:200-203.

31. Sader HS, Jones RN, Gales AC, Silva JB, Pignatari AC. SENTRY antimicrobial surveillance program report: Latin American and Brazilian result for 1997 through 2001. Braz J Infect Dis 2004; 8:25-79.

32. d'Azevedo PA, Dias CAG, Lemos SK, Bittencourt JAF, Teixeira LM. Antimicrobial susceptibility among Enterococcus isolates from the city of Porto Alegre, RS, Brazil. Braz J Infect Dis 2004; 35:199-204.

33. Sader HS, Gales AC, Pfaller MA, Mendes RE, Zocolli C, Barth A, et al. Pathogen frequency and resistance patterns in Brazilian hospitals: summary of results from three years of the SENTRY Antimicrobial Surveillance Program. Braz J Infect Dis 2001; 5:200-214.

34. Sader HS, Jones RN. Antimicrobial susceptibility of gram-positive bacteria isolated from US medical centers: results of the daptomycin surveillance program (2007-2008). Diagn Microbiol Infect Dis 2009; 65:158-162. 